IJBPAS, October, 2020, 9(10): 2684-2690

ISSN: 2277-4998

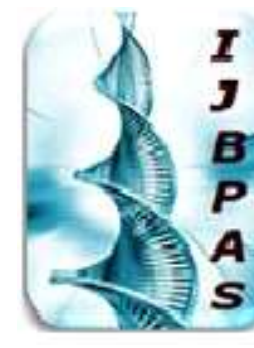

International Journal of Biology, Pharmacy and Allied Seiences (IJBPAS)

'A Bridge Between Caborat ory and Qpada'

WwW.ijbpas.com

PREVALENCE, FORMS AND TYPES OF TOBACCO SMOKING - A LITERATURE REVIEW

\title{
SYAM $\mathrm{S}^{* 1}$ AND MAHESWARI TNU ${ }^{2}$
}

1: PG Student, Department of Oral Medicine and Radiology, Saveetha Dental College, Saveetha Institute of Medical \& Technical Sciences, Chennai

2: Prof. \& Head of Admin., Department of Oral Medicine and Radiology, Saveetha Dental College, Saveetha Institute of Medical \& Technical Sciences, Chennai

*Corresponding Author: Syam S: E Mail: shilpaskottoor@gmail.com

Received 10 ${ }^{\text {th }}$ Feb. 2020; Revised $7^{\text {th }}$ March 2020; Accepted $10^{\text {th }}$ April 2020; Available online $1^{\text {st }}$ Oct. 2020

https://doi.org/10.31032/IJBPAS/2020/9.10.5224

ABSTRACT

Studies report that smoking is the single most preventable cause of death in our society. Yet more than a million die every year in India from tobacco use. Tobacco is a significant contributing factor to the development of oral cancers and also cancers of various other organs. All forms of tobacco have been implicated as causative agents like cigarettes, beedis, pipe smoking as well as chewable products. It is important to differentiate between the numerous forms available as it is suggested that there is considerable difference in the risk. Tobacco companies are fervently using marketing strategies to trade various tobacco products peculiarly targeting the developing countries. Knowledge and awareness regarding tobacco usage and its deleterious effects on health as well as public will aid in reducing tobacco consumption. The aim of this review was to study the prevalence, forms and types of tobacco smoking habit especially in Indian population.

Key words: Smoking, Tobacco, Cigarette Smoking, Beedis, Prevalence, Forms INTRODUCTION

Tobacco consumption is hazardous in any unambiguously demonstrated that tobacco form or disguise. Research has smoke exposure can result in disease, 
disability and death. The International Agency for Research on Cancer (IARC) reveals that smoking tobacco can cause cancer of lung, oral cavity, nasopharynx, oropharynx, hypopharynx, nasal cavity, sinusesand various other organs of the human body [1]. Case control studies have established a strong association between beedi smoking and cancers of oral cavity and other sites with significant link to the number of bidis smoked and the duration of habit [2].

Tobacco smoking involves drawing smoke from burning tobacco, into the mouth and the lungs [3]. The type of smoked tobacco used frequently is the cigarette although other forms are also widely consumed. Smokeless tobacco consists of chewing, sniffing through nose or placing as a wad between cheeks, lips and gums and is popular in certain regions of the world [4].

The smoke from tobacco comprises nicotine, an alkaloid, well absorbed from mucosal surfaces, respiratory tract and skin. It acts at the ganglionic synapse and has a complex action. Nicotine exerts a transient depressive effect on the autonomic nervous system. On the cardiovascular system it has a sympathetic effect resulting in increased heart rate, blood pressure and cardiac output. Combustion of tobacco also yields other chemicals like tar, nitrous oxide and carbon monoxide. Tar and related compounds are known to be carcinogenic. Carbon monoxide raises the levels of carboxyhemoglobin that reduces tissue oxygenation resulting in tissue damage. Cigarette smoking can also cause increased platelet adhesiveness [5].

Tobacco usage is addicting. Most smokers use tobacco regularly as they are addicted to nicotine. Nicotine addiction develops during the first few years of cigarette smoking and most smokers start the habit during childhood or adolescence. A report by the National Household Surveys on Drug Abuse United States revealed that $89 \%$ of daily smokers tried their first cigarette by or at the age 18 [6]. This article highlights the various forms of smoked tobacco, types of tobacco smoking and prevalence of this habit in various parts of the world as smoking is considered to be the most harmful form of tobacco consumption.

\section{Prevalence, forms \& types}

Overall estimates suggest approximately one billion people to be tobacco smokers globally [7]. Gender wise around $30 \%$ of men and 7 $\%$ women fall under the smokers group [8]. As per the reports of Global Annual Tobacco Survey (GATS) reports (2016 -17) there are almost 267 million tobacco users in India alone. Among adults aged above 15, 28.6\% of the population currently uses tobacco 
products (men 42.4\%; women 14.2\%), 21.4\% of adults use smokeless tobacco (men 29.6\%; women $12.8 \%$ ) and $10.7 \%$ of adults smoke tobacco (men 19.0\%; women 2.0\%). Majority of adult smokers reportedly smoke bidis (7.7\% of adults overall) [9]. The Indian Global Youth Tobacco Survey (GYTS) reveals that among youth ages $14.6 \%$ currently use some form of tobacco (boys 19.0\%; girls 8.3\%), 4.4\% smoke cigarettes and $12.5 \%$ use other tobacco products [10]. Approximately half of the states in India are experiencing an increase in smoking among females. Adults in the north-east region are among the most vulnerable population subgroups in India [11]. High prevalence of tobacco use in any form is also reported among school going adolescents aged 13-15 years [12]. Effectiveness of awareness programs in school children have been reported in the literature [13]. These programs mainly focus on harms of cigarette smoking and much less on other forms of smoking and smokeless tobacco. In addition misconceptions have been spread throughout the country as part of indirect promotions by tobacco companies, some claiming that beedis are less harmful than cigars and provide relief from gastritis and constipation. Hence widespread awareness is necessary on health effects of cheaper and local tobacco products in developing countries like India to reduce the prevalence of tobacco associated habits [14].

Tobacco smoking is practiced in the form of cigarettes and beedis or by using some devices or pipes. Owing to the higher cost of cigarettes and imported brands, these are relatively common among higher socioeconomic group, urban areas and western countries. Whereas cheaper and locally made products like beedis, hooka, hookli, chutta, dhumti and chillum [15-18] are more popular among the poorer sections of India.

A cigar is defined as a roll of tobacco wrapped in tobacco leaf or in a substance that contains tobacco. Cigarettes are a roll of tobacco wrapped in paper or in a substance that does not contain tobacco unlike cigars. Cigars contain the same toxic and carcinogenic compounds found in cigarettes and are not a safe alternative to cigarettes. In US market three types of cigars are available namely large cigar, cigarillo and little cigar. A cigarillo is a short and narrow type that contains about 3 grams of tobacco and does not comprise a filter. Beedi, commercially available as small packets of cheap smoking sticks these are handmade by rolling dried rectangular shaped piece of temburni (Diospyros melanoxylon) leaf into a conical 
shape which is filled with sundried flakes of tobacco and secured with a thread. Hookah is a hubble bubble pipe indigenous to India. Made out of wood or metal the device consists of a spherical receptacle filled with water and aromatic substances through which the tobacco smoke passes and enters into the mouth of the smoker. It is known as Shisha in US and Mu'assel in Arab countries. Hookli, another device to draw in tobacco smoke, is a short pipe made of clay around 7 $\mathrm{cm}$ long. It is widely used in some rural areas of India. Chutta is popular in coastal areas of Andhra Pradesh in India, this is a form of reverse smoking in which the burning end is placed inside the mouth while smoking. It is made of coarse rolls of tobacco. WHO has reported that reverse smoking and tobacco chewing account for $50 \%$ of oral cancers.

Dhumti prepared by rolling tobacco leaves inside jackfruit tree leaf, is used for reverse smoking by females whereas the males use it in conventional way. Consumed commonly by the folks of Goa, dried banana leaves are used to prepare this product occasionally. Chillum is a long conical pipe around $10 \mathrm{~cm}$ long, chillum is often wrapped in a wet cloth that provides a filtering effect. The narrow end is inserted into the mouth and used to smoke tobacco either alone or in combination with marijuana. This form is quite popular in northern parts of India [15].

Water pipe tobacco smoking, often associated with Southwest Asia, North Africa and United States consists of a fireclay head, metal body, glass/ acrylic water bowl and leather/ plastic hose. When the smoker inhales through the hose this causes the burning charcoal to heat up the tobacco. The smoke produced travels through the water bowl into the hose [19]. Roll-Your-Own Cigars are hand-rolled cigarettes, used particularly in European countries. These are prepared from loose tobacco known as Shag, cigarette papers and filters all bought separately and preferred since it is cheaper to make oneself than buying other commercially available products. Dokha, originated from Iran and widely used smoking tobacco product in Middle East nations, consists of dried and finely shredded tobacco flakes mixed with herbs and spices.

First hand smoke exposure refers to the tobacco smoke that is directly inhaled by a smoker. The tobacco smoke inhaled by nonsmokers is called second hand smoke exposure also known as environmental tobacco smoke. This may be the smoke released from the burning end of tobacco products or the smoke that a smoker exhales. 
The fact that there is no safe level for second hand smoke further establishes the hazards of smoking in public spaces [20]. The invisible smoke residue left in the air that deposits on furniture and other surfaces is referred to as third hand smoke. This type of smoke exposure has been found to be harmful for babies and toddlers since nicotine has the potential to react with other chemicals in various surfaces to form carcinogens [21].

WHO has classified smokers based on the smoking pattern [22]. Ever-smokers are individuals who had ever smoked for at least 6 months. Current smokers are those smoking tobacco at the time of the survey. Daily or regular smokers are those who smokeat least 1 beedi/cigarette per day. Smokers consuming upto 5 beedis/cigarettes per day are classified as light smokers, between 6 and 20 as moderate smokers, and those smoking more than 20 beedi/ cigarettes per day as heavy smokers. Intermittent group of smokers are those who have a non-daily or intermittent smoking habit [23]. A study conducted among smoking group in India revealed around $41.5 \%$ to be light smokers, $42.9 \%$ to be moderate smokers and $15.6 \%$ to be heavy smokers among men. Among women it was reported that most $(71.8 \%)$ were light smokers, $23.8 \%$ were moderate smokers and $4.4 \%$ were heavy smokers [24].

\section{CONCLUSION}

Each year tobacco use kills about one million Indians. Smoking and exposure to secondhand smoke causes death of about 926,000 people each year [25]. Bidi and cigarette smokers die 6 to 10 years earlier than their non-smoking counterparts and if current trends continue tobacco will account for $13 \%$ of all deaths by 2020 [26, 27]. Awareness programs in schools to curb children and adolescents from falling into the vicious circle of this detrimental habit as well as community programs to spread knowledge about addiction and adverse health effects of tobacco usage to the rural sections is the need of the hour. Additionally people should be taught about the hazards of various forms of tobacco to discourage consumption of cheaper accessible tobacco products too. Furthermore non-smokers can be safe guarded from tobacco smoke by emphasizing on the consequences of second hand and third hand exposure.

Conflict of interest- The authors declare that there is no conflict of interests.

\section{Source of Funding- Self}

Ethical clearance - This article does not contain any studies with human participants or animals performed by any of the authors. 


\section{REFERENCES}

[1] IARC Working Group on the Evaluation of Carcinogenic Risk to Humans. Tobacco Smoke and Involuntary Smoking. Lyon (FR): International Agency for Research on Cancer; 2004.

[2] Ramadas K, Sauvaget C, Thomas G, Fayette JM, Thara S, Sankaranarayanan R. Effect of tobacco chewing, tobacco smoking and alcohol on all-cause and cancer mortality: A cohort study from Trivandrum, India. Cancer Epidemiol. 2010; 34(4):405-12.

[3] Critchley JA, Unal B. Health effects associated with smokeless tobacco: a systematic review. Thorax. 2003 May; 58(5):435-43.

[4] West R. Tobacco smoking: Health impact, prevalence, correlates and interventions. Psychol Health. 2017; 32(8):1018-1036.

[5] Al-Ibrahim MS, Gross JY. Tobacco Use. In: Walker HK, Hall WD, Hurst JW, editors. Clinical Methods: The History, Physical, and Laboratory Examinations. $3^{\text {rd }}$ edition. Boston: Butterworths; 1990. Chapter 40.

[6] Preventing Tobacco Use among Young Peolple. A Report of the Surgeon General. Washington DC: US. Government Printing Office 1994. 65.

[7] Michael Eriksen, Judith Mackay, and Hana Ross. 2012. The Tobacco Atlas, $4^{\text {th }}$ ed. Atlanta, GA: World Lung Foundation.

[8] Gowing, L. R., Ali, R. L., Allsop, S., Marsden, J., Turf, E. E., West, R., and Witton, J. (2015), Global statistics on addictive behaviours: 2014 status report. Addiction, 110, 904- 919.

[9] India Global Adult Tobacco Survey (GATS) 2016-2017.

[10] India Global Youth Tobacco Survey (GYTS) 2009.

[11] Singh A, Ladusingh L. Prevalence and determinants of tobacco use in India: evidence from recent Global Adult Tobacco Survey data. PLoS One. 2014; 9(12).

[12] Rani M, Bonu S, Jha P, Nguyen SN, Jamjoum L. Tobacco use in India: Prevalence and predictors of smoking and chewing in a national cross sectional household survey. Tob Control. 2003; 12 (4).

[13] Reddy KS, Arora M (2005) Global Youth Tobacco Survey (GYTS) Delhi. Indian Pediatr 42: 850-851.

[14] Swadi H, Zeitlin H. Drug education to school children: does it really work?. $\mathrm{Br}$ J Addict. 1987 Jul; 82(7): 741-6.

[15] Chadda R, Sengupta S. Tobacco use by Indian adolescents. Tob Induc Dis. 2002; 1(2): 111-119.

[16] Gupta PC. Survey of sociodemographic characteristics of tobacco use among 99,598 individuals in Bombay, India 
using handheld computers. Tob

Control. 1996 Summer; 5(2): 114-20.

[17] Gupta PC, Sinor PN, Bhonsle RB, Pawar VS, Mehta HC. Oral submucous fibrosis in India: a new epidemic?. Natl Med J India. 1998 May-Jun; 11(3): 113-6.

[18] Bhonsle RB, Murti PR, Gupta PC, Mehta FS. Reverse dhumti smoking in Goa: an epidemiologic study of 5449 villagers for oral precancerous lesions. Indian J Cancer. 1976 Dec; 13(4): 3015.

[19] Cobb C, Ward KD, Maziak W, Shihadeh AL, Eissenberg T. Waterpipe tobacco smoking: an emerging health crisis in the United States. Am J Health Behav. 2010; 34(3): 275-285.

[20] Spiegler, Peter MD. Second-hand Smoke: Not Safe at Any Level. Clinical Pulmonary Medicine (2011). 18(6): 317-318.

[21] Tuma RS. Thirdhand smoke: studies multiply, catchy name raises awareness. J Natl Cancer Inst. 2010 Jul 21; 102(14): 1004-5.

[22] World Health Organization. Document. Geneva, Switzerland: WHO; 1983. Guidelines for the conduct of tobacco smoking surveys for the general population. WHO/SMO/83.4.

[23] Pabst A, Piontek D, Kraus L, Müller S. Substance use and substance use disorders: Results of the 2009
Epidemiological Survey of Substance Abuse (2010). 56(5): 327-36.

[24] Goswami A, Reddaiah VP, Kapoor SK, Singh B, Dwivedi SN, Kumar G. Tobacco and alcohol use in rural elderly Indian population. Indian J Psychiatry. 2005; 47(4): 192-197.

[25] Global Burden of Disease (GBD) 2016. Seattle, WA: Institute for Health Metrics and Evaluation (IHME), University of Washington; 2017.

[26] Jha P et al. A Nationally Representative Case-Control Study of Smoking and Death in India. The New England Journal of Medicine. 2008; 358; 1-11.

[27] Shimkhada R, Peabody JW. Tobacco Control in India. Bulletin of the World Health Organization. 2003; 81: 48-52. 